\title{
El Malbec de Francia: la Denominación de Origen Controlada “Cahors". Historia y perspectivas
}

\author{
French Malbec: Appelation of Origin "Cahors". History and perspectives \\ Pablo Lacoste ${ }^{1 *}$
}

\begin{abstract}
RESUMEN
La Denominación de Origen Controlada de "Cahors" asombró al mundo vitivinícola en 2007 cuando tomó la decisión de adoptar el Malbec como emblema de su imagen corporativa. El significado de esta medida fue romper la tradición de la viticultura europea, centrada en el terroir y adoptar la estrategia del Nuevo Mundo Vitivinícola, focalizada en el varietal. La DOC Cahors puso en marcha una vía intermedia que se apoya tanto en el varietal como en la cultura y el patrimonio vitivinícola. El artículo examina la vitivinicultura de Cahors, cuna del Malbec, desde una perspectiva histórica, desde la Antigüedad romana hasta nuestros días como bases culturales de su estrategia actual. El tema es relevante en la viticultura del Cono Sur, donde el Malbec ocupa un papel significativo: Argentina (34.000 hectáreas) es el primer productor mundial y Chile (1.900 hectáreas) es el tercero.
\end{abstract}

Palabras clave: Malbec, denominación de origen, Cahors.

\begin{abstract}
The Cahors Apellation of Origin stunned the wine world in 2007 when he decided to take the Malbec as an emblem of their corporate image. The significance of this decision was to break the tradition of European viticulture, terroir-focused and to join the New World Wine strategy, focused on varietal. AOC Cahors launched a middle way that supports both strain and wine culture and heritage. The article examines the wine of Cahors, the birthplace of Malbec, from a historical perspective, from Roman antiquity to the present day for the cultural basis of its current strategy. The issue is relevant in viticulture of South America, where the Malbec plays a significant role: Argentina (34,000 hectares) is the world's largest producer and Chile (1,900 hectares) is the third.

Key words: Malbec, wine region, Cahors.
\end{abstract}

\section{Introducción}

En 2007 la Denominación de Origen Controlada (DOC) Cahors sorprendió al mundo vitivinícola con un anuncio paradójico: a partir de ese momento su imagen corporativa se asociaba con el Malbec. Esta decisión marcó un hito histórico en la estrategia comercial del Viejo Mundo, pues en lugar de conservar el tradicional énfasis en el terroir, el eje se trasladó al varietal, tendencia propia del Nuevo Mundo donde existe una mirada que relativiza el papel del terroir (Pszczólkowski, 2014) y la estrategia comercial se focaliza en el varietal y la innovación (Villanueva, 2014). Si durante largos siglos los vinos de América habían observado y reconocido a los europeos como referentes, esta situación se comenzó a revertir a partir del caso Cahors.
Detrás de la decisión de la DOC Cahors estaba el exitoso caso del Malbec argentino. Con el comienzo del siglo XXI, la vitivinicultura argentina comenzó a exportar sus vinos en cantidades relevantes. Las empresas comenzaron con el envío de los vinos disponibles, incluyendo sus diversas variedades. Pero rápidamente la demanda se volcó preferentemente hacia el Malbec. Este sorpresivo éxito comercial llevó a la viticultura argentina a focalizarse cada vez más en el fortalecimiento de esta variedad. $\mathrm{La}$ superficie cultivada con Malbec en Argentina subió de 10.000 hectáreas en 1990 a 16.500 en 2000 y 34.000 en 2012. Poco a poco se consolidó la tendencia, hasta llegar a constituir alrededor del 50\% de las exportaciones de vino embotellado. Argentina se consolidó como "la patria del Malbec", con el cultivo de 33.866 hectáreas de este varietal. Esta tendencia

\footnotetext{
1 Universidad de Santiago de Chile. Román Díaz 89, Providencia, Santiago, Chile.

* Autor por correspondencia: pablo.lacoste@usach.cl
} 
fue emulada también en la región, particularmente en Chile, donde la superficie cultivada con Malbec pasó de 900 hectáreas en 2000 a 1.980 una década después (INV, 2012; SAG, 2013).

El éxito comercial del Malbec argentino inspiró también a los vignerons de Cahors. Estos ya tenían aprobada su DOC en 1971, y elaboraban vinos principalmente con Malbec. Además, esta cepa había surgido precisamente en esta región, entre la Antigüedad y la Edad Media. En este contexto, se tomó la decisión de cambiar la estrategia y fortalecer la identidad del vino local a partir del varietal. Actualmente Cahors cultiva 4.000 hectáreas de Malbec y apenas representa el $10 \%$ de la superficie mundial, mientras Argentina mantiene su liderazgo con el $85 \%$. De todos modos, los viñedos de Cahors pueden crecer; actualmente se estima que tiene un potencial de 21.000 hectáreas. Además, en su etapa de apogeo (1880) se llegaron a cultivar 80.000 hectáreas (Gascó y Hautfeuille, 2011).

¿Puede ser Cahors una amenaza para la hegemonía del Malbec argentino? Tal vez sea prematuro responder esta pregunta. En todo caso, el Malbec de Cahors ha comenzado a penetrar con cada vez más fuerza en los mercados de EE.UU., uno de los lugares principales del Malbec argentino. Ante estas perspectivas, resulta interesante conocer la historia de los vinos de Cahors, cuna del Malbec. El objetivo del presente artículo es describir y explicar el proceso histórico de esta localidad, desde la Antigüedad hasta nuestros días.

\section{Discusión Bibliográfica}

El Malbec ha sido estudiado principalmente por su desarrollo en Argentina, donde se cultiva el $80 \%$ de esta variedad en el mundo. Menor interés ha dedicado hasta ahora el mundo académico al estudio del Malbec en Cahors, donde se encuentra el $10 \%$ de la superficie cultivada con este varietal. En general se trata de trabajos focalizados, que abordan alguna etapa acotada de su rica evolución. El período más estudiado corresponde a los siglos XIII y XIV, durante la dominación inglesa, tanto en obras generales de historia vitivinícola (Unwin, 2001) como en trabajos específicos sobre el vino en esa región (Soyez, 1978). Esa etapa fue retomada por Beezley (2005) para insertar el Malbec de Cahors dentro de la historia general de este cepaje. Pero en su texto, el papel de Cahors se desdibuja a partir del siglo XIX, cuando esta cepa se traslada al sur de América, se adapta a los climas y suelos de Argentina y Chile, se propaga en sus viñedos y se consolida como cepa emblemática de Mendoza. Estas obras dejan pendiente lo que ocurrió con el Malbec en Cahors desde el siglo XIX hasta la actualidad.

Es importante también el aporte que han realizado los historiadores locales, dedicados al estudio de la evolución de la ciudad de Cahors y su entorno (provincia del Quercy primero, departamento de Lot, después). Los trabajos de Fourgous (1991), Vire (2000), Gascó et al. (2011), Saint-Marty (2011) y Daymard (2013) permiten interpretar la evolución de la viticultura de Cahors en su contexto político, económico, social y cultural, desde la Antigüedad romana hasta nuestros días, particularmente lo que ha ocurrido en los dos últimos siglos, base del actual proyecto de esta DOC.

\section{Materiales y Métodos}

El presente trabajo tiene características de investigación exploratoria. El Malbec de Cahors todavía no ha sido abordado de manera focalizada por el mundo académico. Los historiadores franceses están recién diseñando un proyecto para examinarlo, a cargo del doctor Leonard Laborie (Universidad de Paris-Sorbona). De todos modos, la extensa y rica historia de esta localidad ha generado una abundante bibliografía, de esta se entrega en este trabajo una revisión y análisis general. A ello se suma un viaje realizado para conocer las bodegas y viñedos de Cahors en terreno ( $15 \mathrm{al} 19$ de junio de 2014). Se recorrieron viñedos, bodegas y chateaux; se asistió a dos calicatas y cinco catas de vinos de Cahors. Se realizaron reuniones y entrevistas con los actores involucrados en la DOC, incluyendo a viticultores, agrónomos, agentes comerciales, sommeliers, estrategas de marketing e historiadores profesionales. Se pudo reunir el material disponible, generado por la DOC Cahors, junto con una rica bibliografía local de difícil acceso en América Latina. Sobre la base de estos elementos, y con una mirada multidisciplinaria, enfocada en los métodos propios de las Ciencias Sociales, se ha elaborado este artículo.

\section{Cahors, capital del departamento de Lot}

El centro histórico de producción de Malbec ha sido tradicionalmente la ciudad de Cahors, localidad ubicada en el sudoeste de Francia, 25 leguas al 
norte de Toulouse, 50 leguas al este de Burdeos y 100 leguas al oeste de Avignon. Cahors se levanta junto al río Lot, afluente del Garona, por estos se llega al puerto de Burdeos, sobre el Atlántico. El departamento de Lot tiene actualmente una superficie de $5.200 \mathrm{~km}^{2}$ y una población de 172 mil habitantes. El nombre "Malbec" es muy tardío, pues se debe a un viticultor húngaro del siglo XIX que intentó promover el cultivo de esta cepa en Francia. En cambio la variedad Malbec (antes llamada "cot") se encuentra entre las cinco más antiguas y proviene "directamente de la domesticación de vides salvajes por parte del hombre primitivo" (Choren, 2003).

Históricamente Cahors fue la capital de la provincia del Quercy, territorio de 12.000 kilómetros cuadrados en la región del mediodía francés, cerca de los Pirineos. Por su localización central dentro de este territorio, Cahors ejerció un singular liderazgo político y económico en este espacio. La población del Quercy llegaba a 235.000 habitantes en 1699 y 386.000 en 1786 (Gascó, 2011). El departamento de Lot se creó en 1790 y alcanzó una población de 414.000 habitantes. Posteriormente el emperador Napoleón desmembró algunas partes y en 1808 constituyó el actual departamento de Lot. Con su reducción territorial disminuyó también su población; pero debido a la prosperidad económica de sus actividades agrícolas y agroindustriales comenzó a crecer nuevamente. A mediados del siglo XIX su población llegó a 295.000 habitantes, de estos 13.000 residían en Cahors. Siguieron etapas de crisis económicas y sociales, signadas por la plaga de filoxera (de filo, hoja y xera, hemíptero de pequeño tramaño que se alimenta de la raíz de la viña: Peñín, 2000) que destruyó los viñedos y las guerras mundiales, con la ocupación alemana. Como resultado, la población cayó a la mitad. A fines del siglo XX se estabilizó la población, y a comienzos del siglo XXI comenzó nuevamente a crecer. Actualmente el departamento de Lot tiene $5.200 \mathrm{~km}^{2}$, con una población de 172.000 habitantes y su capital, Cahors, 20.000 pobladores.

El eje articulador del paisaje es el río Lot, que atraviesa todo el departamento de este a oeste. Se trata de un curso de agua relativamente navegable, que tiene un ancho de 100 metros y 1,40 metros de profundidad media. Para entender Cahors es indispensable considerar el papel de los ríos durante mil años en la vida social, económica, política y cultural de la región. En Europa continental las principales vías de transportes y comunicaciones fueron las carreteras romanas en la Antigüedad y los ferrocarriles y telégrafos en la modernidad. La situación fue muy diferente en el período intermedio, cuando no había un Estado capaz de conservar la infraestructura romana, ni tampoco había tecnología para construir los ferrocarriles. Por tanto, en la Edad Media las grandes arterias por donde circulaba la vida económica y social eran los ríos navegables. Ellos marcaban los grandes ejes del transporte, el comercio y las comunicaciones en la región. Y este fue el sentido del río Lot que, a lo largo de 480 kilómetros, atraviesa buena parte del sur de Francia. Tras nacer en el macizo central, a 1.600 metros de altitud, sus aguas corren hacia el este, hasta desembocar en el Atlántico, previa confluencia en el Garona. El río Lot ofrecía relativamente buenas condiciones de navegabilidad. Por sus aguas circulaban los comerciantes para llevar el carbón y el hierro que se extraía en las montañas, hacia los puertos del Atlántico; y en el sentido inverso, por el Lot se transportaban los alimentos a insumos del centro para los mineros del este. Además, los vinos de Cahors salían con fluidez hacia el Atlántico para llegar a los mercados británicos.

El río Lot era el complemento ideal para movilizar los productos del país. Las tierras y climas de esta región resultan adecuadas para la producción agrícola y agroindustrial. Situada a una altitud de 300 metros snm y con un régimen de precipitaciones de 600 milímetros anuales, el departamento de Lot se ha distinguido tradicionalmente por el cultivo de viñas, frutales (manzanas, nogales, ciruelas, castañas), trufas, tabaco, fresas y ganadería menor (ovejas y cabras) y productos agroindustriales (vinos, quesos, conservas). La historia de estos pueblos estuvo marcadamente signada por estos productos para los que habían evidentes ventajas comparativas; gracias al río Lot se podían producir cantidades considerables porque los excedentes se comercializaban en mercados externos.

Las condiciones naturales de esta región sedujeron a los romanos que la incorporaron al Imperio en un lugar preferente. La ciudad de Cahors, llamada Divona, fue un dinámico centro de actividades económicas, sociales, políticas y culturales durante la época romana. Allí se levantaron notables obras públicas, incluyendo un acueducto de $30 \mathrm{~km}$ de longitud, teatro con capacidad para de 5.000 plazas, un puente sobre el río Lot y un centro termal. Parte de estas colosales construcciones todavía son visibles en la ciudad (Gascó, 2011; Daymard, 
2013). Se dieron entonces las condiciones para la expansión agrícola. "La paz romana permitió a los cadurques aumentar la extensión de los cultivos; plantas extranjeras importadas por los romanos fueron aclimatadas, tales como-se dice- el nogal, el castaño, el cerezo, el parel. Hacia esta época, la viña se extendió sobre nuestras colinas, produciendo un vino comparado desde el siglo VII con los mejores crus de Italia" (Saint-Marty, 2011). En efecto, en el período romano se produjo el nacimiento de la tradición vitivinícola de Cahors. Algunos autores sostienen que alrededor del año 20 después de Cristo se introdujo allí una cepa llamada basilica o biturica, lo que contribuyó al desarrollo de la viticultura en la región (Soyez, 1978). Otros académicos se inclinan a pensar que la llegada de la vid se demoró un siglo más (alrededor del año 150 después de Cristo), procedente de Italia, trasladada por los romanos. También se considera posible que esta cepa haya llegado de otras zonas de Europa. Lo que está claro es que allí se cultivó tempranamente esta variedad (Beezley, 2005). La tradición vitivinícola del sudoeste francés se remonta a los primeros años de la era cristiana. Los habitantes de esta región desarrollaron muy pronto el hábito de cultivar las viñas, elaborar los vinos; parte de la producción se consumía en la localidad, y parte se comercializaba, aprovechando las facilidades para el transporte fluvial. En este contexto surgió el Malbec, en un momento todavía no establecido con precisión.

La ubicación geográfica de Cahors facilitó las exportaciones de vinos. Los barriles de vino se trasladaban en pequeñas balsas por los ríos Lot y Garona, y llegaban rápidamente a los circuitos comerciales. Durante el Imperio Romano el vino de Cahors fue apreciado por las élites. Así se refleja en obras de los autores clásicos, sobre todo Horacio y Virgilio (Beezley, 2005). Desde el punto de vista comercial, la localización de Cahors significaba una desventaja respecto de los vinos de la cuenca del Mediterráneo, que llegaban en forma más expedita a los mercados de las principales metrópolis imperiales. Pero la situación se invertía en relación con los mercados del norte, particularmente los de Gran Bretaña. La conquista de esa región por parte de las legiones romanas generó un nuevo mercado para los vinos; los caldos del sudoeste francés pasaron a tener ventajas comparativas en proporción a los mediterráneos. Por tanto, ya en la Antigüedad se produjo el nexo entre los vinos del sudoeste francés y los consumidores del espacio británico, esto contribuyó a estimular la economía de esta región y definir su vocación vitivinícola (Soyez, 1978).

\section{Crisis y apogeo del vino de Cahors en la Edad Media}

En la Edad Media la situación cambió completamente para Cahors. Sin la protección del Estado, sus fértiles tierras y sus riquezas se convirtieron en codiciado botín para los bárbaros; y el río Lot, de facilidad para el transporte se transformó en amenazante vía de acceso para los invasores. La comunidad de Cahors se aprestó a enfrentar los siglos más complicados de su historia. En el año 574 Cahors fue saqueada e incendiada (Viré, 2000; Saint-Marty, 2011). Las invasiones de los musulmanes también dejaron huella en la región. En 731 un ejército conducido por el hábil táctico Abd el Rahman, invadió la Gasconia, asoló e incendió varios pueblos, entre ellos Cahors, "matando sin piedad a todos los infieles que se rehusaban a adorar a Mahoma; muchos aquitanos salvaron su vida mediante una conversión rápida, ello ocasionó una recristianización vigorosa tras la partida de los sarracenos" (Soyez, 1978; Saint-Marty, 2011). A las invasiones musulmanas siguieron las penetraciones de los normandos en el siglo IX. Los hechos de violencia se multiplicaron después, durante la Guerra de los Cien Años, signada por las constantes invasiones inglesas a la provincia del Quercy.

La traumática experiencia de las invasiones externas marcó profundamente los imaginarios sociales en esta región. La respuesta fue buscar medios eficaces de defensa que protegieran las personas y los bienes ante la constante agresión. Ante la lejanía del rey, los pobladores se apiñaron alrededor de las grandes familias y se empoderó la nobleza territorial y el sistema feudal (Viré, 2000; Saint-Marty, 2011). Estas transformaciones se reflejaron en la arquitectura, con el florecimiento de las redes de castillos y fortalezas con muros de piedra en todo el Quercy, particularmente en las riveras del río Lot. Alrededor de estas formidables fortalezas surgía el mercado, las viviendas modestas, las iglesias y los burgos. Poco a poco se fue constituyendo el actual paisaje regional, dominado por esas construcciones defensivas.

A pesar del entorno de conflictos y turbulencias, los viticultores de Cahors siguieron adelante con el cultivo de sus viñas y la elaboración de sus vinos. Su 
perseverancia les permitió consolidar su prestigio. En la Alta Edad Media el vino de Cahors fue reconocido en el siglo VII por el obispo de Verdún (Beezley, 2005). Pero el impulso más trascendente se debió a la acción de una mujer, Leonor de Aquitania, fue artífice de la reconexión de estos vinos con el mercado británico. Sobre esta historia conviene considerar algunos detalles.

Leonor de Aquitania (1122-1204) fue una de las mujeres más destacadas de la Edad Media europea (Pernoud, 2009). Tuvo un poder considerable al controlar el ducado de Aquitania, que se extendía del Loria hasta los Pirineos. Fue símbolo de la mujer que toma sus propias decisiones y vive intensamente. Personaje fascinante, llamó la atención de los cronistas de su época, tanto laicos como eclesiásticos. Su vida fue rescatada por la literatura y la Historia, sobre todo en Leonor de Aquitania (1969), la recurrentemente editada obra de la historiadora francesa Régine Pernoud, y también fue llevada al cine en El león en invierno (1968), con magistrales interpretaciones de Peter O'Toole y Katherine Hepburn.

La vida de Leonor de Aquitania se cruza con la historia del Malbec en un punto clave. $\mathrm{Su}$ casamiento con Enrique Plantagenet (1152) estableció un estrecho lazo entre su ducado y las islas británicas. La boda se planificó como un acuerdo dinástico y político, pero sobre esa base institucional se generaron las condiciones para establecer también conexiones económicas y comerciales. Se aceitaron los mecanismos del intercambio de bienes y servicios entre ambas regiones, y dentro de este contexto se produjo la llegada de los vinos de Cahors a los mercados ingleses. Este fue el inicio del proceso de construcción de la cultura de apreciación del Malbec entre los consumidores británicos (Unwin, 2001).

El lazo político del sudoeste francés con Inglaterra tuvo una larga duración. Se extendió desde el matrimonio de Leonor con Enrique (18 de mayo de 1152) hasta la caída de Burdeos en manos de los franceses (19 de octubre de 1453). Aquitania fue inglesa durante tres siglos. Fue un período decisivo en la historia política, económica, social y cultural de la región, a lo largo de este se consolidó su vocación vitivinícola.

La demanda del mercado inglés significó un gran estímulo para la vitivinicultura regional. Los puertos del Atlántico se convirtieron en dinámicos polos de intercambio comercial. Muchas veces la producción de vino no lograba satisfacer la demanda. En este contexto no tardaron en surgir conflictos de intereses, sobre todo entre la Corona, los sectores dominantes de los puertos y los viticultores del interior del país que debía necesariamente pasar por esos lugares para colocar sus productos.

\section{Cuando los ingleses cultivaban el Malbec}

El rey Ricardo Corazón de León, hijo y sucesor de Leonor de Aquitania se preocupó de construir una institucionalidad que, a la vez, promovía, aseguraba y aprovechaba la producción y el comercio de los vinos regionales. Entre otras iniciativas, estableció un impuesto para el transporte de carga por el río Garona, el que tenía por objetivo, principalmente, el vino del interior de esa región, este incluía el vino de Cahors. Estas tasas fueron luego mantenidas por su hermano Juan sin Tierra, y el hijo de este, Enrique III. En 1219 el impuesto se fijó en dos peniques por barril de vino transportado por ese río. Ello significaba una carga para los productores pero también la oportunidad de contar con una institucionalidad que atendiera sus intereses, sobre todo frente al puerto de Burdeos. En general, la administración inglesa en esta región contribuyó a estimular la producción y el comercio. "El senescal Thomas de Valkafara se ocupó de la navegación del Lot e hizo retirar en Puy-l'Evêque las rocas que obstaculizaban el descenso de los barcos" (Saint-Marty, 2011).

La rivalidad entre los vinos de Cahors y los vinos de Burdeos generó numerosos conflictos. Sobre todo porque los productores de Burdeos trataron de aprovechar su posición estratégica, al controlar el puerto sobre el Atlántico en su propio beneficio. Los viticultores locales presionaron a las autoridades de la ciudad para imponer trabas e impuestos al ingreso de los vinos de Cahors a Burdeos. Esta medida era un golpe mortal para la viticultura de Cahors, porque Burdeos era la salida natural de estos vinos por el Lot y más adelante el Garona.

Los conflictos de intereses entre viticultores del interior y porteños no tardaron en llegar a la corte, y fueron solucionados al más alto nivel. "En 1225 Enrique III prohibió a los Jurats de Burdeos detener u obstaculizar de alguna manera los vinos de Cahors que pasaban por el Gironda y que estaban bajo su protección personal" (Soyez, 1978).

El vino de Cahors recibió atención especial de dos reyes ingleses y franceses. Si Enrique III lo 
situó bajo su protección personal un siglo más tarde, Eduardo III se interesó en este producto y comenzó a llamarlo "vino oscuro de Cahors" (Beezley, 2005). Paralelamente, en Francia también se notó la valoración de la realeza. "En 1302 Felipe el Hermoso y la reina pasaron por Cahors de camino a Toulouse. En 1328 Carlos IV, viniendo de Rocamadour, fue recibido en gran pompa por los cónsules cadurcianos. Los oficiales municipales fueron a esperar al rey hasta Labastide y, a su llegada, a las puertas de la ciudad, le obsequiaron 25 bueyes, 120 ovejas, 50 toneladas de avena, 160 litros de vino, 4 quintales de velas y medio quintal de confituras. Estos presentes en especie eran destinados a las necesidades de la numerosa escolta que los personajes importantes debían llevar con ellos a causa de la inseguridad de los caminos" (Saint-Marty, 2011). Posteriormente, "en 1364 el príncipe de Gales visitó las principales villas y ciudades de su ducado. En junio pasó ocho días en Cahors donde los cónsules le obsequiaron 24 pipas de vino. El príncipe confirmó los privilegios de la ciudad y el año siguiente decidió que los vinos de Cahors solo tendrían que pagar un derecho de cinco centavos por pipa para ingresar a Burdeos" (Saint Marty, 2011). Poco después fue el turno del duque de Anjou el que, de paso por Cahors en 1370, confirmó las libertades comunales y el año siguiente "el rey dispensó a los cadurcianos de todo nuevo impuesto durante veinte años y les acordó el derecho de comerciar por todo el reino sin pagar derechos por ello 'por haber sacudido los primeros, el yugo de los ingleses a pesar de la crueldad y el terror que esta nación inspiraba a los pequeños pueblos del ducado"” (Saint Marty, 2011).

La constante rivalidad de ingleses y franceses por el control del territorio contribuyó a dinamizar la producción vitivinícola regional. Los ingleses importaron regularmente el vino de Cahors en los siglos XIII y XIV. La temporada 1308-1309 obtuvo una de las marcas más altas del comercio de vino de Cahors, con 850.000 hectolitros. Los ingleses no solo compraban vinos de esa región, sino que también invirtieron en ella, atraídos por la perspectiva del negocio y el prestigio de este producto. Se generó así un significativo flujo de capitales británicos hacia la viticultura del sudoeste francés, ello contribuyó al debilitamiento y la definitiva desaparición de la viticultura inglesa (Unwin, 2001).

Se produjo entonces un ciclo dorado de la viticultura de Cahors en un contexto de dinámica económica regional. "El vino de la rivera del Lot constituía el elemento principal del comercio con los países del norte; nuestros compatriotas exportaban también tejidos de lana, utensilios de estaño y de plata fabricados por los artesanos de nuestras villas. De regreso, ellos traían telas inglesas, pescado de mar salado o seco" (Saint-Marty, 2011). La prosperidad activó la producción, los negocios, las finanzas y la vida intelectual de esta ciudad. En 1308 se comenzó a construir el pont Valentre, luego reconocido como Patrimonio de la Humanidad por la UNESCO. En la percepción de la época la ciudad de Cahors era una localidad relevante, con intensa vida social y comercial, con obras públicas que atraían ingenieros y trabajadores, además de financistas y empresarios.

La prosperidad comercial estuvo asociada con la expansión del crédito y las finanzas. Los capitales contribuyeron a levantar la actividad económica y acelerar su expansión. Ello llevó a los empresarios locales a adquirir cierto nivel de especialización en estas complejas operaciones. "Hacían también cambios de monedas, operaciones que la diversidad de las especies tendía a hacer todavía más activas. Cahors se convirtió en un centro financiero con el otorgamiento de préstamos a interés; como resultado, el nombre del gentilicio de esta ciudad (caorsien) sirvió durante largo tiempo como sinónimo de usurero" (Saint-Marty, 2011). En el marco de los valores medievales, de condena al capitalismo en general y al otorgamiento de préstamos a interés, estas tendencias fueron demonizadas en la época. Estos imaginarios fueron captados por los intelectuales y creativos de la época, como se reflejó en la obra literaria más importante de entonces: la Divina Comedia. Dante consideró adecuado mencionar a Cahors como "ciudad del pecado". Por este motivo la incluyó en el infierno de su Divina Comedia (XI: 50), al mismo nivel que Sodoma. La presencia de Cahors en la obra cumbre de la literatura italiana muestra el nivel de visibilidad que había alcanzado la ciudad en la primera década del siglo XIV. En el imaginario de Europa mediterránea de la Edad Media, Cahors era un punto de referencia, reconocido por su arquitectura, sus grandes obras públicas, su actividad económica y sus dinámicos centros financieros.

\section{La tradición cultural de Cahors}

Resulta notable el desarrollo cultural e intelectual de la región en esta época, como se reflejó en la expansión de las instituciones educativas, sobre todo 
los colegios (Daymard, 2013; Foissac, 2010). A su vez, la gravitación geopolítica de esta localidad creció en 1309 cuando la corte del Papa se trasladó de Roma a Avignon. Poco después, un hijo de Cahors fue promovido al papado como Juan XXII (1316-1334).

La gestión de un hijo de Cahors como Sumo Pontífice de la Iglesia católica fue el reflejo de la relevancia alcanzada por esta ciudad en los planos de la vida económica, social y cultural en la época. El papado de Juan XXII se encuentra muy presente todavía en el imaginario social de la ciudad. Se recuerdan los lugares por donde circuló y vivió el papa de Cahors. Existe también un circuito turístico que evoca su figura. En las calles de la ciudad se ve también cartelería alusiva. La figura del papa Juan XXII ocupa en Cahors el papel que en las repúblicas latinoamericanas tienen los héroes de las guerras de la independencia. Los viticultores de Cahors también reivindican este papado como parte de su historia. De acuerdo con estas tradiciones, en esa misma época se cultivó la cepa de Cahors (presumiblemente Malbec) en el palacio papal de Avignon (Beezley, 2005; Gascó, 2011). Una tarea pendiente de los historiadores franceses sería ratificar o rectificar esta tradición.

La Universidad de Cahors fue uno de los logros más importantes de la gestión del papa Juan XXII. Esta universidad se fundó en 1331. De esta manera, la ciudad del Malbec se incorporó al selecto club de ciudades universitarias de Francia, formado entonces por solo cuatro miembros más: París (1150), Toulouse (1229), Montpellier (1289) y Avignon (1303). De esta forma Cahors consolidaba su posición de liderazgo intelectual, científico y cultural en el sudoeste francés. Esta universidad, junto con la red de colegios y escuelas, realizó una fecunda labor durante más de cuatro siglos (Foissac, 2010; Saint-Marty, 2011; Daymard, 2013). La presencia de estas casas de estudios significó un gran impulso a la vida cultural del Quercy, proceso que tuvo duraderos efectos. Hacia fines del siglo XVIII, en vísperas de la revolución, el $45 \%$ de los hombres sabían al menos escribir su nombre (Gascó, 2011). Aunque la Universidad de Cahors fue cerrada en 1751, la labor de colegios y escuelas se multiplicó. En 1870 la tasa de escolaridad de la población de este departamento llegaba al 100\% (Gascó, 2011). Esto marca un contraste notable con la realidad del sur de América. En Chile y Argentina, durante el período colonial, la mayoría de la población era analfabeta; las políticas educativas avanzaron lentamente y recién se hicieron sentir con claridad un siglo más tarde.

\section{Rumbo a la modernidad}

El siglo XV fue una etapa de transición. Tras el final de la guerra de los Cien Años, con la derrota inglesa (1453) llegaba el momento de la reconstrucción de los viñedos y las rutas comerciales. La prosperidad de Francia en este período permitió una mejora notable en la infraestructura de transporte. Hubo mejoras en la navegabilidad de los ríos, como así también en los puertos. La promoción de Clément Marot (1495-1544), poeta nacido en Cahors, contribuyó a captar la atención de Francisco I por este vino. Como resultado, el monarca ordenó plantar una viña con vino de Cahors (probablemente Malbec) en el castillo y palacio de Fontainebleau (Beezley, 2005). El poder de la monarquía para conducir la moda y el prestigio se mantuvo cerca de los vinos de Cahors por largo tiempo. Durante las guerras de religión de fines del siglo XVI, Enrique de Navarra (futuro rey Enrique IV) conquistó la ciudad de Cahors e hizo una valoración positiva de sus vinos.

En la segunda mitad del siglo XVII y durante el siglo XVIII, la marcha del vino de Cahors retomó vigor, impulsada por la prosperidad de Francia, que se encontraba en la cima de su poder. Los reinados de Luis XIV y Luis XV marcaron el apogeo de Francia como primera potencia mundial. En este contexto se realizaron importantes obras de infraestructura que favorecieron la producción y comercialización del vino. Esclusas, canales, caminos y mejoras en los puertos contribuyeron a facilitar la tarea de los viticultores, sobre todo para comercializar mejor sus productos. "Por orden de Colbert se impulsó un amplio proyecto de mejoramiento de la ribera del Lot, incluyendo la construcción de 21 esclusas doble, 'a la manera de Holanda'. Los ingenieros más reputados, entre los que se destacaba el caballero de Clerville, se encargaron de supervisar los trabajos ejecutados entre 1664 y 1669" (Saint-Marty, 2011).

El mejoramiento de las condiciones de navegación del Lot contribuyó a activar el comercio. Los barcos remontaban el río llevando vinos de Cahors, cereales y productos exóticos hacia el macizo central de Francia, y regresaban cargados de carbón y otros minerales. Además, en el siglo XVIII se inició la construcción de la carretera 
conocida actualmente como Ruta Nacional 20, que insertaba Cahors un ágil eje de circulación nortesur. A partir de entonces el viaje de esta ciudad a París se completaría en una semana (Gascó, 2011).

La antigua rivalidad entre Cahors y Burdeos volvió a estallar al comenzar el siglo XVIII. Los cónsules de Burdeos establecieron nuevas tasas y trabas para la libre circulación del vino de Cahors en su jurisdicción. Además de los impuestos cada vez más elevados por barrica de vino ingresada, se establecieron fechas regulatorias. En 1701 el Consejo puso en vigencia una norma de 1500 , por la que los vinos de Cahors "solo podían ingresar a Burdeos entre el 21 de diciembre y el 1 de mayo siguiente. Después de esta fecha todos los vinos sin vender debían ser liquidados a precio vil o enviados de vuelta a su lugar de origen" (Saint-Marty, 2011). Con estas políticas, solo posibles por la tolerancia del gobierno central, se contribuyó al proceso general de evolución de la viticultura francesa hacia el modelo actual, con la hegemonía de Burdeos debido a su privilegiada posición geográfica y su decisión de asegurarse el control monopólico de los mercados, en detrimento de otras regiones vitivinícolas de ese país, incluyendo a Cahors, que se vio perjudicado por esa actitud autoritaria de Burdeos.

En los siglos XVII y XVIII el vino de Cahors alcanzó nuevas marcas en su proyección internacional. El zar Pedro el Grande (1672-1725) tuvo especial interés por el vino de Cahors. Este se servía regularmente al zar (Saint-Marty, 2011). Se cuenta que el noble vino del sur francés ayudó al monarca ruso a preservar su salud y hasta contribuyó sanar una úlcera de estómago (Beezley, 2005). Por su iniciativa se introdujeron cepas de Malbec en el imperio ruso, particularmente en la región de Crimea. Los popes rusos, durante el zarismo, usaron el vino de Cahors para celebrar la misa (Gascó, 2011). La propagación del Malbec en Rusia se consolidó durante Catalina la Grande (1729-1796), quien dio un decidido impulso al traslado de cepas desde Francia.

El papel de los vinos de Cahors en la política interna del siglo XVIII francés es otro tema interesante. Las nuevas ideas y propuestas políticas afectaron el tradicional desenvolvimiento de la industria. A mediados de aquella centuria, los economistas de moda impulsaron ideas contrarias a la viticultura; propiciaron la reconversión de los campos para priorizar el cultivo del trigo. Fue una etapa complicada porque desde el Estado se impulsó una ideología contraria a la cultura de la vid y el vino. Concretamente, "la viña fue considerada malhechora" (Saint-Marty, 2011). En cierta forma, se estaba preanunciando la política de demonización del vino y el alcohol que llegarían a su máxima expresión a comienzos del siglo XXI. El segundo problema fue la crisis económica en la región del mediodía francés y la tendencia a la emigración de sectores empobrecidos. Se produjo entonces la reacción de las autoridades locales en defensa de la cultura vitivinícola regional. En el marco de la crisis, en 1715 el Parlamento de Toulouse reivindicó la importancia estratégica de los viticultores y estableció la prohibición de abandonar la tierra antes de completar las tareas culturales de la viña (Saint-Marty, 2011). El tercer punto crítico surgió con motivo de la Revolución Francesa y la tendencia de los campesinos a asaltar los castillos y construcciones emblemáticas de la nobleza. En varios casos, los castillos fueron asaltados, saqueados e incendiados. En este contexto, los castellanos del departamento de Lot buscaron una alternativa: ante la presencia de las masas rebeldes en las puertas de sus chateaux, optaron por entregarles los preciosos vinos de Cahors. Con este medio se lograron preservar varios castillos de la zona (Saint-Marty, 2011). entre ellos .

\section{El Malbec y su expansión en el siglo XIX: llegada a Chile y Argentina}

En el siglo XIX se produjo la expansión del Malbec hacia viñedos de otros continentes, particularmente Asia y América. Esta corriente se vio favorecida por las innovaciones tecnológicas de los transportes, sobre todo los ferrocarriles y la navegación a vapor. Las distancias se acortaron, lo mismo que los tiempos de viaje. Además, el auge de las teorías del librecambio como paradigma político y económico vigente en esos años contribuyó a estrechar los lazos comerciales, económicos y culturales entre los distintos mercados. En este contexto muchos productos llegaron a lugares que hasta entonces habían permanecido aislados, y entre ellos viajó el Malbec. A ello se sumaron otras tendencias del siglo XIX como la creación de escuelas de agronomía y estaciones experimentales, que contribuyeron a la difusión de las plantas hacia aquellos países donde las condiciones de climas y suelos lo permitían. En 1828 se puso en marcha la hacienda de Crimea, en donde el príncipe Vronontsov cultivaba miles de cepas de uva francesa, incluyendo 
Malbec (Beezley, 2005). Poco después esta variedad llegaría al Cono Sur de América.

El Malbec llegó a Chile en la década de 1840. En el marco de la apertura política y cultural generada a partir de la Independencia, la clase dirigente chilena comenzó a mirar hacia Francia con creciente interés y con ambiciones de superación. En este contexto, uno de los aspectos que se procuró incorporar fue la vitivinicultura, incluyendo cepas y técnicas francesas de elaboración del vino. De esta manera, llegarían a Chile especialistas franceses como René Lefebvre, Claudio Gay y Michel Aimé Pouget, quienes motorizaron importantes cambios en la vitivinicultura nacional, acentuando las tendencias francesas (Briones, 2007). Junto con ellos hubo también otros franceses que realizaron aportes significativos, cuyas propuestas se difundían por medio de las nuevas instituciones creadas precisamente para tal fin, como la Sociedad Nacional de Agricultura (fundada en 1838) y la Quinta Normal de Santiago (1841). En estas condiciones se produjo la llegada de las cepas europeas al fértil suelo chileno (Del Pozo, 2014).

En el plano institucional, el espacio más importante de este proceso fue la Quinta Normal de Santiago. Fundada en 1841, su nombre se inspiraba en el de la Escuela Normal de París, donde se cultivaban distintas plantas, particularmente vides. La Quinta Normal de Santiago operó como una estación experimental en el sentido de introducir nuevas especies y variedades de plantas europeas, adaptarlas a los suelos y climas americanos y luego difundirlas en la región para mejorar la producción agrícola y agroindustrial.

Poco después esta tendencia se extendió hacia Argentina. Sarmiento regresó a su país y promovió la fundación de la Quinta Normal de Mendoza. Siguiendo el modelo de Francia y Chile, esta Quinta Normal se propuso incorporar nuevas variedades de cepas como medio para mejorar la industria vitivinícola nacional. Esta iniciativa fue acogida por el gobernador de Mendoza Pedro Pascual Segura y su ministro de gobierno Vicente Gil. El 17 de abril de 1853 se presentó el proyecto ante la legislatura provincial con vistas a fundar una Quinta Normal y una Escuela de Agricultura. La Cámara de Representantes abordó el proyecto y lo aprobó con fuerza de ley (Girini, 2006). En conmemoración de este hecho, Wines of Argentina, agencia encargada de promover las exportaciones de vino, eligió el 17 de abril como Día Mundial del Malbec, que comenzó a celebrarse a partir de 2011.
La llegada del Malbec a Mendoza se vio favorecida por la larga tradición vitivinícola de la región. Los viticultores mendocinos llevaban entonces tres siglos de experiencia en el cultivo de la viña y la elaboración del vino. Los viticultores locales no solo dominaban las técnicas de manejar las viñas, sino que, además, habían demostrado capacidad de incorporar cepas nuevas, como el moscatel de Alejandría y los derivados de esta y la uva criolla chica, es decir, el torrontés y las distintas variedades de moscatel (Lacoste, 2010a y 2010b; 2013).

Entre 1853 y 1890 se produjo el proceso de adaptación y propagación del Malbec en los suelos y climas de Mendoza. Fue un trabajo silencioso y eficaz que tuvo como protagonista al viticultor criollo, que tuvo oportunidad de aplicar en el Malbec la experiencia acumulada en los siglos anteriores. De esta forma, cuando llegó el ferrocarril a Mendoza, en 1885, y cuando comenzaron a llegar masivamente los inmigrantes europeos a esta provincia, al comenzar el siglo XX, el Malbec ya estaba plenamente adaptado a Mendoza.

\section{Apogeo y crisis de los vinos de Cahors}

El vino de Cahors alcanzó su apogeo en el siglo XIX. La etapa de mayor expansión se registró entre 1850 y 1880 , cuando la superficie cultivada trepó de 50.000 a 80.000 hectáreas. La producción llegó a 450.000 hectolitros, destinadas principalmente a la exportación (Gascó, 2011). Este vino llegó con fluidez a los mercados del norte de Europa (Inglaterra, Alemania, Holanda). También intentó conquistar el oeste, sobre todo a EE.UU. y el este, para llegar a Rusia (Beezley, 2005).

Resulta notable el fenómeno del vino de Cahors en relación con los ferrocarriles, porque a diferencia de otras regiones vitivinícolas de Europa y América, el período de apogeo de estos vinos no tuvo relación con las conexiones ferroviarias. En efecto, en el caso de Mendoza, el período del boom vitivinícola regional (1885-1914) comenzó, precisamente, a partir de la conexión ferroviaria de esta ciudad con Buenos Aires (1885). En Chile también fue importante el ferrocarril como transformador de la vida económica regional e impulsor de la industria de la vid y el vino. En cambio, en Cahors ocurrió el fenómeno inverso. Esta ciudad recién quedó integrada a las redes ferroviarias nacionales en 1891, cuando se libró al servicio la línea de Toulouse a París, tocando Cahors. Además, esta tardía conexión tuvo escasa 
incidencia, pues la filoxera ya había destruido la mayor parte de los viñedos de Cahors.

La plaga de filoxera causó un impacto sin precedentes en la viticultura europea en general, y francesa en particular, muy especialmente en Cahors. Como se sabe, la producción vitivinícola francesa cayó de 59 millones de hectolitros en 1863 a 25 millones en 1884. Más de un millón y medio de hectáreas de viñedos fueron destruidos por la filoxera. En Cahors, los viñedos quedaron seriamente dañados en 1877. La superficie cultivada experimentó una brusca caída. El $80 \%$ del viñedo quedó perdido. En 1903 apenas se cultivaban 20.000 hectáreas en Cahors y en 1919 ya no se comercializaba vino local (Gascó, 2011). En los años posteriores se trató de recuperar el viñedo, pero con nuevos problemas. A las vidas perdidas durante la Primera Guerra Mundial, siguió la ocupación alemana en la Segunda. Para completar esta infortunada historia, la helada de 1956 asestó un nuevo golpe a la viticultura local, llegando casi a aniquilar en su totalidad los últimos restos de las viñas.

Los antiguos viñedos fueron reemplazados por otros cultivos como trufas, nueces, tabaco, fresas, castaños y manzanos. También se impulsó la ganadería menor, sobre todo de ovejas y cabras. Sobre esta base se pusieron en marcha los quesos, entre los cuales se destaca la Denominación de Origen Rocamadour. De todos modos, esta reconversión productiva no alcanzó para sostener a la población regional.

La crisis de la viticultura generó una notable corriente migratoria, que comenzó a reducir la población regional. Esta tendencia se profundizó con las guerras mundiales, en ellas murieron muchos pobladores de esta localidad. Particularmente negativa fue la experiencia de la ocupación alemana. Como resultado, el departamento de Lot perdió la mitad de su población, al pasar de 295.000 a 150.000 habitantes entre 1870 y 1950 . Esta es la base de la situación actual de esta región, que apenas ha logrado evolucionar. Recién a fines del siglo XX se pudo estabilizar la población de Lot, que llegó a 160.000 habitantes en 1999 y 172.000 en 2008 .

\section{Presente y proyecciones del vino de Cahors}

Parte de esta recuperación demográfica se debe a la resurrección de los viñedos de Cahors. En el último medio siglo comenzaron nuevamente a plantar sus tradicionales cepas de Malbec y a elaborar sus vinos. Un papel central en este proceso cupo a las cooperativas, que permitieron generar sinergia entre los pequeños viticultores participantes. $\mathrm{La}$ cooperativa Parnac, con 180 miembros, ocupó un papel central en este proceso, llegando a elaborar un cuarto de la producción total de vinos de Cahors. También tomó fuerza la Denominación de Origen de Cahors, que se ocupó de articular las estrategias de marketing de los pequeños viticultores de la región. En poco tiempo alcanzaron resultados relevantes, y lograron convertirse en la segunda DOC del sudoeste de Francia (Gascó, 2011). La DOC Cahors se formalizó en 1971. A partir de entonces se puso en marcha un proceso que ha logrado consolidarse a corto plazo.

La DOC Cahors llegó en 2011 a cultivar una superficie de 3.800 hectáreas de viñedos, exclusivamente dedicada a uvas tintas para vinificar. Las normas de la DOC establecen que las viñas no pueden producir más de 50 hectolitros por hectárea. El vino de Cahors debe tener al menos $70 \%$ de Malbec; se puede complementar con Merlot o Tanat. Con estas uvas se elaboran 183.446 hectolitros de vino, el $20 \%$ en cooperativas. El $80 \%$ restante está en manos de 240 productores particulares ("Dominios" o "Chateaux"). El 30\% de la producción se exporta a EE.UU.

Las claves de la nueva viticultura de Cahors se encuentran en el énfasis de la pequeña propiedad y en la elección del Malbec como cepa emblemática. La pequeña propiedad es una tradición que se mantiene vigente en la región. La viticultura local se encuentra distribuida entre cientos de pequeños productores. Muchos de ellos han logrado hacer viable sus empresas gracias a la participación en cooperativas. Un paso importante en este sentido se verificó en 2006 cuando cuatro bodegas cooperativas se agruparon en Vinovalie con el lema "El grupo es mejor que el mejor del grupo".

Un giro histórico en la viticultura de Cahors se verificó en 2007. Ante el éxito alcanzado por el Malbec de Argentina en los mercados internacionales, los productores de Cahors resolvieron cambiar su estrategia de marketing, mediante la focalización de su cepa emblemática, el Malbec. A partir de entonces, en lugar de promoverse como "vino de Cahors", comenzaron a trabajar con la imagen de "CahorsMalbec". Como emblema se ha diseñado un timbre redondo con el lema "CahorsMalbec Destination France".

Para diferenciarse de Argentina, la estrategia de Cahors consiste en distinguirse por su historia y 
su identidad francesa. La oficina de marketing de la DOC utiliza principalmente tres lemas para comunicar la imagen del producto: "El Malbec del Hemisferio Norte", "El Malbec de Francia" y "El Malbec de los Reyes, los Papas y los Zares". La idea era posicionarse como el mejor Malbec del mundo, apuntando a un segmento más alto en precio que el Malbec de Argentina y de Chile. La propuesta se complementa con la realización del patrimonio histórico cultural del Departamento de Lot. La infraestructura medieval de los castillos e iglesias de piedra se incorpora como pareja conceptual de los viñedos en los paisajes del vino de Cahors. A ello se suma la experiencia de los maridajes con la gastronomía local, con la puesta en valor de los quesos con denominación de origen (Rocamadour) y las distintas variedades de fois gras, entre otros productos.

\section{Conclusión}

Los vinos de Cahors han planteado una audaz estrategia, al romper con la tradición europea de énfasis en el terroir, e incorporarse a las corrientes del Nuevo Mundo vitivinícola, con eje en el varietal. El significado de esta situación es el fortalecimiento del prestigio del Malbec y la legitimación de la estrategia de los varietales. Estos elementos son positivos para el desarrollo futuro de la viticultura de los países emergentes, como Argentina y Chile.

Paralelamente, el caso de Cahors resulta notable como paradigma del empleo de patrimonio como herramienta central del marketing vitivinícola. La oficina de marketing de la DOC Cahors ha reservado un papel activo dentro de su estrategia, a los paisajes y recursos culturales del Departamento de Lot, como mecanismos que contribuyen a fortalecer la imagen corporativa del "Malbec europeo" y para agregarle valor al producto.

Evidentemente, las historias de Francia son muy distinta de las de Argentina y Chile. En el sur de América no vivieron reyes, emperadores ni papas, factores ideales para la construcción del prestigio de un producto comercial. Tampoco gobernaron figuras emblemáticas de la historia universal, como Ricardo Corazón de León. Algo parecido ocurre con la notable arquitectura de castillos de piedra tallados junto al río Lot.

Sin embargo, los países del Cono Sur han tenido sus propios itinerarios culturales, con procesos interesantes, cargados de significado e interés. No tienen castillos de piedra, pero sí cuentan con un valioso patrimonio natural y cultural, incluyendo la singularidad de sus bellezas escénicas. En todo caso, la diferencia principal, hasta el momento, se encuentra en la diferente actitud de valoración de los recursos como parte importante de la imagen y el valor del vino y en la cultura del maridaje con la gastronomía local, lo que implica la voluntad de desarrollar otras DO de productos alimentarios como los quesos. Así como Cahors tuvo capacidad de observar el caso del Malbec argentino para mejorar sus estrategias comerciales, Argentina y Chile tienen mucho que aprender de Cahors.

\section{Agradecimientos}

Los autores agradecen al Proyecto Fondecyt 1130096.

\section{Literatura citada}

Beezley, W.

2005. La senda del Malbec: la cepa emblemática de Argentina. Universum, 20(2): 288-297.

Briones, F.

2007. Los inmigrantes franceses y la vitivinicultura en Chile. Universum, 22(1): 126-137.

Choren, G.

2003. El gran libro del Malbec argentino. Buenos Aires, Planeta, 200 pp.

Daymard, J.

2013. Le vieux Cahors. Monographies des villes et villages de France. Paris, Le livred'histoire (reimpresión de la edición de 1927) 277 pp.

Del Pozo, J.

2014. Historia del vino chileno: desde 1850 hasta hoy. 2 ed. Santiago de Chile: Lom, 306 pp.
Foissac, $\mathrm{P}$.

2010. Histoire des collèges de Cahors et Toulouse (XIV-XV siècles). Cahors, La Louveéditions, 575 pp.

Fourgous, M.

1991. Le vieux Quercy. Usages anciens. Cahors, Bibliotheque de la maison des oevres. 2 tomes: tome I: 267 pp.; tome II: $250 \mathrm{pp}$.

Gascó, J.; Hautefeuille, F.; Rousset, V.; Bergues, M.; Gaston Bazalgues, J. et; Guy Astruc, J.; Coustou, J.C.; Jacob, J.P.; Sourzat, P.; Sarthe, N.

2011. Lot. Histoire, art, traditions, langue et littérature, milieu natural, économie et societé. Paris, Cristine Bonneton Editeur, 320 pp.

Girini, L.

2006. La enoteca, patrimonio de la tierra del vino. Mendoza, Fondo Vitivinícola, 86 pp. 
Instituto Nacional de Vitivinicultura (INV).

Superficie de Viñedos. Anuario 2012, http://www.inv.gov.ar/ inv_contenidos/pdf/estadisticas/anuarios/2012/superficie/ Registro.pdf consultado: 4 /nov/2014.

Lacoste, P.; Yuri, J. A.; Aranda, M.; Castro, A.; Quinteros, K.; Solar, M.; Soto, N.; Gaete, J.; Rivas, J.

2010a. Variedades de uva en Chile y Argentina (1550-1850): genealogía del torrontés. Mundo Agrario, 10 (20), 1-37.

Lacoste, P.

2010b. Parrales, braceros y cepas de cabeza: el arte de cultivar la viña en Mendoza y San Juan (1561-1869). Historia, 43 (1): 5-40.

Lacoste, $\mathrm{P}$.

2013. Vinos de capa y espada. 300 años de vitivinicultura en Argentina (1561-1861). Mendoza, Antucurá. Prólogo de Prudence Rice, 355 pp.

Peñín, José.

2000. Vino. Diccionario Espasa. Madrid, Editorial Espasa Calpe, $811 \mathrm{p}$.

Pernoud, R.

2009. Leonor de Aquitania. Primera edición en español: Madrid, Espasa Calpe, 1969. Últimaedición: Barcelona, Acantilado, $336 \mathrm{pp}$.
Pszczólkowski, $\mathrm{Ph}$.

2014. "Terroir” y "Climats”: ¿realidad o quimera? Revista Iberoamericana de Viticultura, Agroindustria y Ruralidad, 1 (1): 13-19.

Saint-Marty, L.

2011. Histoire populaire du Quercy desoriginesà 1800.Paris, Le livred'historie, $343 \mathrm{pp}$.

Servicio Agrícola Ganadero (SAG)

Catastro Vitícola Nacional 2013, http://www.sag.cl/noticias/ sag-presenta-informe-del-catastro-viticola-nacional-2013 Consultada: 04/Nov/2014.

Soyez, J.M.

1978. Quand les Anglais vendangeaient l'Aquitaine. D'Aliénor à Jeanne d'Arc. Paris, Fayard, 254 pp.

Villanueva, E.

2014. La innovación como causa del éxito exportador vinícola del Nuevo Mundo Anglosajón, Revista Iberoamericana de Viticultura, Agroindustria y Ruralidad, 1 (1):1-12.

Viré, A.

2000. Le Lot. Padirac, Rocamadour, Lacave. Guide du Touriste, du Naturaliste et de l'Archéologue, 1907. Reedición facsimilar: Les éditions du Bastión, 307 pp.

Unwin, T.

2001. El vino y la viña. Geografía histórica de la viticultura y el comercio del vino. Barcelona, Tusquets, 529 pp. 